\title{
A Constituição da Inteligência: Uma Abordagem Psicanalítica
}

\author{
Regina Orgler Sordi ${ }^{1}$ \\ Universidade Federal do Rio Grande do Sul
}

\begin{abstract}
Resumo
O artigo procura situar o tema da inteligência humana na perspectiva psicanalítica, em especial, da contribuição de Silvia Bleichmar, explorando como a mente humana desenvolve a atividade intelectual a partir de seus estados embrionários. É reconhecida a contribuição da epistemologia genética desenvolvida por Jean Piaget que nos permite compreender a capacidade de construir sistemas simbólicos a partir de esquematismos sensório-motores. São também salientadas algumas convergências entre o pensamento piagetiano e o pensamento psicanalítico. O que é enfatizado neste artigo, entretanto, é que a contribuição psicanalítica sobre os primórdios da inteligência tem sido bem menos estudada, embora de grande interesse teórico e clínico. A inspiração teórica deste artigo, a partir dos estudos de Bleichmar, apoia-se fortemente em Freud, mas fundamenta-se de forma mais decisivana orientação da escola francesa de Jean Laplanche. O artigo procura mostrar que, para alcançar a objetividade das estruturas lógicas, caracterizadas pelas categorias da lógica aristotélica - classificação, espaço, tempo, causalidade e negação - o psiquismo realiza um ativo trabalho de ligação dentro da mente que se inicia nas primeiras inscrições do outro humano sexualizado e que necessita implantar a repressão originária, única operação capaz de organizar a lógica do pensamento secundário. Enfatiza, ao final, que a contribuição sobre uma teoria das origens do psiquismo, no que concerne ao desenvolvimento da inteligência, permite ajudar nos estudos sobre os problemas de aprendizagem, diferenciando as dificuldades secundárias à construção do conhecimento dos transtornos que remetem ao não constituído do ego.

Palavras-chave: Inteligência; origem; implantação da pulsão; repressão originária.
\end{abstract}

\section{The Constitution of Intelligence: A Psychoanalytical Approach}

\begin{abstract}
This paper aims to discuss human intelligence in the psychoanalytical perspective, particularly considering the contribution of Silvia Bleichmar who explores how human mind develops the intellectual activity from the embryonic states. It is recognized the contribution of genetic epistemology developed by Jean Piaget which allows to understand the capacity to build symbolic systems from sensory-motor schemes. There is also pointed some convergence between the genetic psychology and the psychoanalytic thought. What is stressed in this article, however, is that the contribution of psychoanalysis about the origins of intelligence has been less studied, although it is of most interest both theoretically and clinically. The theoretical inspiration of the paper relies on Freud's theory but it is more definitely grounded on the French school of Jean Laplanche. It tries to show that to reach the objectivity of logical structures, characterized by the categories of the Aristotelian logic - classification, space, time, causality, denial-the psychism does an active work of mind connection which starts in the first inscriptions of the other sexualized human and has to implant the originary repression, the only one able to organize the logic of the secondary thought. It stresses, at the end, that the contribution about a theory of the origins of psychism, concerning the development of intelligence is of great help in the studies about learning disabilities, as it differentiates learning difficulties due to secondary causes of the disorders which address to the lack of constitution of the ego.

Keywords: Intelligence, origin, implant of pulsion, originary repression.
\end{abstract}

O tema deste artigo diz respeito à constituição da inteligência a partir da perspectiva psicanalítica. Interessa-nos explorar os meios pelos quais a mente humana desenvolve a atividade intelectual ou os processos cognitivos a partir de seus estados embrionários. No campo psicológico, os estudos de Jean Piaget sobre o nascimento da inteligência (1936/1978) revigoraram o debate sobre os processos cognitivos que, até os primórdios do século XX, estruturavam-se em torno do esquema clássico estímulo-resposta.

Em termos gerais, a inteligência é definida como um modo de adaptação do indivíduo ao meio, sendo este concebido em sua acepção complexa, como um meio que é simultaneamente físico, social, simbólico e histórico-cultural. Ao definir a inteligência como adaptação, devemos diferenciar entre o ser biológico (no qual as condutas estão guiadas por certa recepção de informação précodificada geneticamente) e os modos específicos da inteligência humana, na qual o conhecimento ocupa um lugar central e permite uma operatória não pré-formada. A lógica operatória, na medida em que não é um dado natural, herdado geneticamente, passará a ser

${ }^{1}$ Endereço para correspondencia: Universidade Federal do Rio Grande do Sul, Rua Ramiro Barcellos, 2600, 90035 003, Porto Alegre, RS. Fone: (51) 33165283. o grande desafio da epistemologia genética. Piaget definirá a inteligência como um funcionamento que precede e engendra esta lógica, sendo concebida como a totalidade das estruturas mentais que o organismo tem à disposição em determinado período do desenvolvimento e que tem por função essencial estruturar o universo, assim como o organismo estrutura o meio ambiente imediato (Piaget, 1973).

Assim, ao falarmos em inteligência, tanto no campo piagetiano, quanto no campo psicanalítico, não referimos apenas à capacidade de apropriar-se da realidade para sobreviver - algo que todo animal pode realizar desde os começos da vida - mas da capacidade de criar uma realidade sobre a base de uma imaginação produtiva. $\mathrm{O}$ que caracteriza o ser humano é sua capacidade de construir sistemas simbólicos - sistemas de pensamento - que subvertem suas necessidades básicas e criam necessidades não existentes na natureza. $\mathrm{O}$ pensamento, por sua vez, é compreendido como um átomo de simbolização e tanto Piaget (1982) quanto os estudiosos da psicanálise parecem concordar que seria difícil imaginar um pensamento sem linguagem, pois o pensamento, strictu sensu implica a representação de objetos para além do campo perceptivo real e supõe um instrumento de expressão simbólica. É por esta razão, que Piaget irá precisar, ao longo de sua teoria, que não podemos falar em um pensamento 
sensório-motor, mas sim, em uma inteligência sensório-motora, já que o pensamento significa o funcionamento ativo da inteligência operatória que, por sua vez, seria quase um sinônimo da inteligência humana, propriamente dita, prolongamento dos esquematismos sensório-motores. Num sentido lato, porém, a psicanálise nos permite falar de um pensamento vinculado a uma modalidade que é alucinatória, não relacionada diretamente ao objeto da realidade (Freud, 1895). De forma aproximada, Piaget descreve a inteligência sensório-motora na qual predominam quadros perceptivos sem permanência de objeto num sujeito que exibe uma ação primitiva radicalmente inconsciente de si próprio, embora sua descrição não nos autorize a utilizar o termo pensamento (Piaget, 1970).

Se nos ativéssemos à construção da inteligência no paradigma da epistemologia genética, teríamos farto material bibliográfico e experencial sobre o qual tecer idéias e comentários. Ao percorrer o tema, porém, na perspectiva psicanalítica, que é objetivo deste artigo, nos deparamos com uma bibliografia bem mais escassa. Vamos encontrar nos trabalhos de Bleichmar (1993, $1995,1999)$ um esforço para compreender os primeiros tempos de constituição da inteligência - da passagem de um pensamento fundado no fenômeno da alucinação primitiva aos esforços humanos para ter acesso aos processos que organizam os conhecimentos. Em suas palavras (1999):

Sobre os tempos de constituição da inteligência e sobre a função da repressão originária vocês terão de limitar-se ao que eu possa enunciar, já que não há trabalhos prévios. Comecemos por retomar a idéia de um primeiro tempo de vida... (p. 271)

Aceitemos, pois, empreender essa viagem.

\section{Os Primórdios da Inteligência}

Tempo I: A Implantação da Pulsão

Comecemos por pensar um primeiro tempo da vida, provido de montagens adaptativas fragilmente instaladas. É um primeiro tempo em que o infans está atravessado pelo mundo da necessidade, da sobrevivência. Neste tempo se produzirá o que a psicanálise francesa pontuou como um momento em que, indo o infans em busca da satisfação de certas necessidades, encontrase com o outro humano. Neste ponto inicial do desenvolvimento humano, mas também das idéias deste trabalho, Bleichmar (1993) desenvolve uma vasta teorização sobre sua compreensão do inconsciente, diferenciando seu posicionamento, sob certos aspectos, tanto da Metapsicologia freudiana, quanto do pensamento lacaniano:

O fato de que o inconsciente não seja sede dos instintos no sentido biológico do termo, não implica que a estrutura da linguagem constitui integralmente seu campo... Assim como a pulsão nãoé um ser abstrato, biológico, definido em si mesmo, senão que é efeito da intrusão sexualizada do outro humano, desprendida da biologia comum a todos os homens e enraizada em uma história singular da sexualidade do sujeito psíquico, a linguagem préconsciente não é também a estrutura do código a que se referem os lingüistas, senão que é o resíduo dos discursos particulares nos quais o sujeito se constitui. (Bleichmar, 1993, p. 48)
Em sua obra Projeto de uma Psicologia Cientifica (1895), Freud oferece uma compreensão sobre o mecanismo de efetivação de uma ação específica, que apresenta uma semelhança com a idéia acima (apesar de que, mais adiante, neste trabalho, veremos que pode haver ação específica sem que isso gere um campo de representações, simbolizações).

O organismo humano é, em princípio, incapaz de levar a cabo essa ação específica. Ela se efetua por meio da assistência alheia, quando a atenção de uma pessoa experiente é atraída para o estado em que se encontra a criança mediante a condução da descarga pela via de alteração interna. Essa descarga adquire, assim, a importantíssima função secundária de comunicação, e o desamparo inicial dos seres humanos é a fonte primordial de todos os motivos morais. (p. 422)

$\mathrm{Na}$ perspectiva freudiana, há nestes primeiros tempos, um cumprimento do princípio de inércia neuronal: a tendência a zero, da tensão, por descarga. Mas a única tensão que é descarregada é a tensão de auto-conservação, da necessidade biológica. A quantidade de leite, por exemplo, pode ser sempre a mesma durante um período: o leite entra, cancela o estímulo e a tensão de necessidade desaparece. $\mathrm{O}$ grande paradoxo da função materna (Bleichmar, 1999) é que, no momento em que satisfaz necessidades, a mãe inclui excitações, introduz algo que não estava previsto no programa da natureza, produzindo uma profunda alteração nos modos automáticos de descarga e quebrando, de entrada, a inércia neuronal. A partir disso, o aparelho se recarregará com tensões de caráter interno, produto de seus sistemas de representações ativados pelas zonas erógenas impulsionadas no ato do cuidado correspondente. Assim, segundo a autora, o que caracteriza a alucinação primitiva não é somente o fato de que o bebê alucine o seio em sua ausência, mas que o alucine ainda em sua presença; vale dizer, recobre o objeto presente com certos elementos que provêm de traços desprendidos do objeto originário. Não se trata de pensar o bebê como um psicótico que alucina a presença de um objeto inexistente, mas de dar conta de que a inscrição residual de certos traços do objeto, leva a que, quando apareça novamente a tensão da necessidade, produza-se um movimento desejante que consiste em um ato: investimento de uma marca mnêmica. Esta, por sua vez, não reflete o objeto do mundo, mas é um conglomerado de traços que acompanham a experiência de satisfação. Esta multiplicidade de traços, por sua vez, dá conta de que o objeto construído não só não é idêntico à coisa do mundo, res extensa, mas que inclui restos do objeto do mundo e da ação efetuada pelo sujeito, restos do sujeito mesmo e isto lhe outorga uma espessura própria a partir do ponto de vista de sua realidade.

Cria-se, assim, uma realidade nova, realidade de "representação", que já não está "fora”, nem tampouco, "dentro", mas está destinada a um espaço que um dia será o de "dentro"- um lugar que se inscreve como de excitação e de ligação, ao mesmo tempo. De excitação, na medida em que nunca mais a descarga poderá ser totalmente anulada (porque não se trata de uma descarga apenas a nível biológico; junto ao alimento que sacia a fome, o outro excita, produz mensagens enigmáticas no infans, introduzindo um plus que não pode ser evacuado) e de ligação, porque cada vez que apareça uma tensão - 
seguindo o modelo freudiano - um estímulo se converterá numa excitação e, não sendo passível de evacuação, terá de ligar-se de algum modo. Podemos chamar a este primeiro objeto de alucinação primitiva, um primeiro núcleo de simbolização que, paradoxalmente, sendo um efeito do real externo, nem reflete a realidade exterior, nem está destinado a conhecê-la.

O que caracteriza o paradoxo do simbolismo humano, em suas origens, é que não tem nenhum objetivo de apreensão da realidade exterior, não tem nenhum sentido de domínio sobre o mundo: seu único objetivo é o domínio sobre a excitação interna. A simbolização humana surge, assim, de uma espécie de corte radical do adaptativobiológico e os traços do objeto só operam como elementos-índices dos processos de prazer-desprazer, de gratificação, de reequilibração; tratam-se de objetos que possibilitam uma via de resolução das tensões endo-psíquicas. E o objeto alucinatório, que não é a cópia do objeto exterior, se caracteriza por estar destinado a múltiplas transcrições. Neste sentido, o modelo da carta 52 nos parece muito fecundo:

...Como você sabe, estou trabalhando com a hipótese de que nosso mecanismo psíquico formou-se por um processo de estratificação: o material presente em forma de traços de memória estaria sujeito, de tempos em tempos, a um rearranjo segundo novas circunstâncias - a uma retranscrição. Assim, o que há de essencialmente novo a respeito de minha teoria é a tese de que a memória não se faz presente de uma só vez, mas se desdobra em vários tempos; que ela é registrada em diferentes espécies de indicações. (Freud, 1896, p. 317)

O pensamento que Freud apresenta no modelo das retranscrições nos parece muito fecundo, já que vemos os distintos sistemas operarem possibilitando as passagens de um em outro, mas com barreiras entre si: alguns elementos passam e outros ficam. Estas múltiplas transcrições caracterizam o fato de que a memória tenha múltiplas formas e, em sua forma primeira, trata-se mais de uma marca do que de uma verdadeira memória. $\mathrm{O}$ sujeito nada sabe sobre esta marca e seus nexos com o exterior terão sido cortados, de modo que pode apenas recriar o objeto sem, em verdade, recordá-lo.

Se não é o mundo exterior, no sentido estrito, o objeto da simbolização primitiva, como o sujeito se reencontra com o objeto do mundo, enquanto objetivo, aquele que possibilita a operatória sobre o real?

Uma vez que se tenham constituído as primeiras representações, que podem ser transcritas, estas conformam sistemas de marcas que tomam para seu cargo uma subversão da ordem natural: as linhas de interesse sobre o mundo que a natureza havia definido do ponto de vista da auto-conservação são substituídas por linhas de interesse libidinal, linhas de investimento. Uma vez implantadas estas representações de base, o infans se lançará sobre os objetos do mundo, ainda quando esteja movido por necessidades biológicas como a fome, a partir de traços guiados pelas linhas de prazerdesprazer. À diferença de um animal, o infans pode comer coisas inadequadas, porque uma vez constituída sua oralidade, o que vai caracterizá-la é certo nível não de indiscriminação, mas de uma discriminação guiada por variáveis que não são naturais. Os investimentos libidinais produzem uma alteração de tudo o que tenha a ver com a percepção, no sentido de que a cognição

Psicologia: Reflexão e Crítica, 2005, 18(3), pp.337-342 do mundo se põe a serviço não da auto-conservação, mas do reencontro com os indícios dos objetos de prazer.

A própria experiência sensorial não é o resultado de uma relação imediata do sujeito natural com o objeto da necessidade, mas o efeito de uma interseção operada pelo adulto - não só provido de linguagem, mas também de sexualidade - entre o infans e os objetos do mundo.

Vemos aqui uma alteração importante no que diz respeito a uma idéia tradicional sobre o quê constitui a experiência , já que não há experiência humana, no sentido estrito do termo, que estabeleça uma relação direta, não mediada com os objetos do mundo.

Não há uma 'objetividade' que não se veja atravessada por aquilo que em psicanálise denominamos de ordem libidinal, sendo a grande pergunta, com respeito à inteligência, como se constitui e de que ordem é esta objetividade necessária do conhecimento, enquanto "objetivo", sempre efeito de uma construção na qual há mediações 'objetais'- provenientes de objetos de amor e destinadas a eles. (Bleichmar, 1999, p. 279)

O objeto real, o seio, introduz algo que produz certas marcas, certas inscrições. Estas inscrições operam como fonte constante de pulsação interna no infans, quebrando assim o princípio da inércia neuronal e obrigando a um trabalho psíquico, que será o motor do progresso, do pensamento. Sem esta intervenção que vem fazer um curto-circuito da percepção animal, no homem, não se constitui a percepção humana.

Verificamos, assim, que pode haver ação especifica, sem que isso gere um campo de representações, de simbolizações. Devemos revisar, aqui, o conceito de ação específica, ao nível das primeiras representações, já que estas não remetem à resolução da autoconservação, ainda quando o objeto sobre o qual recaia a autoconservação devenha paradoxalmente objeto de excitação. Se há uma ação específica na alimentação, esta é operada pelo semelhante humano, já que o ser humano, em suas origens, não pode fazer-se cargo de si mesmo. O que Freud não incluiu em sua análise sobre este ponto, é o fato de que o outro humano é um ser sexualizado, oferece ao infans algo que tem a ver com uma sexualidade pela qual já está atravessado (Bleichmar, 1999).

Neste ponto, podemos nos apoiar fortemente na proposta de Lacan sobre o fato de que o infans vai em busca da satisfação da necessidade e se encontra com o desejo do outro e que este outro não é neutro, que se caracteriza por ser humano, desejante e sexualizado. Talvez, nesta idéia, resida a maior virtude do pensamento lacaniano inaugurado na primeira metade do século $\mathrm{XX}$, que foi o de marcar o caráter exógeno e de cultura da fundação do inconsciente: realçar, mediante uma inversão da perspectiva freudiana, o movimento que, a partir da estrutura do Édipo, faz o sujeito inicialmente submergir em um mundo sexual e simbólico que constitui a premissa de base da constituição do inconsciente.

O giro diferente que se aponta é que estamos diante de zonas de regulação que ingressam na sexualidade do infans e que não são capazes de segregar representações. Para que haja algo da ordem do representacional tem que haver um plus que não evacue a zero e esse plus é de proveniência exógena, alheia. 
Assim como na Antropologia ou na Economia Política se ensina que, para que haja intercâmbio tem que haver excedente, aqui podemos ver que, para que haja pensamento, tem que haver excedente; e excedente quer dizer algo que não se reduz ao leite, algo que não se reduz a satisfazer a ordem da natureza. Neste sentido, há que sair tanto da idéia de que a mãe dá um leite maravilhoso, quanto de que dá um leite envenenado, já que o paradoxo que a mãe inaugura é que, ao oferecer o leite, que é também excitação, produz o movimento paradoxal, voltado tanto para a inteligência, quanto para a loucura: algo maravilhoso ou envenenado, pré-requisitos que vão articular a capacidade simbólica da criança.

Neste circuito, o que é importante é que há um outro que está pensando e significando ao lactente e simultaneamente comunicandose na "linguagem da paixão" (Laplanche, 1988), cuja característica é ser irredutível às potencialidades polissêmicas da linguagem: e este é o pré-requisito da linguagem comunicacional; há algo que faz a enunciação do infans antes que ele possa enunciar-se. Antes que a criança diga "eu quero", ela enuncia: "Ana quer", anunciando-se a partir do outro até chegar na forma do "eu".

Este é um primeiro tempo, um tempo onde se produzem estas primeiras inscrições que se caracterizam por haverem perdido a referência ao objeto.

Tempo II: Repressão do Auto-erotismo, Constituição da Repressão Primária:

Em um segundo tempo, estas inscrições têm que encontrar modos de ligação para não ficarem liberadas às moções pulsionais, cujas conseqüências podem ser desastrosas para o aparelho psíquico, fraturando-o ou empobrecendo-o. $\mathrm{O}$ inconsciente não antecede ao ego, mas é correlativo da repressão originária e a constituição do ego; isto não quer dizer que antes de sua fundação não hajam representações, mas tais representações não são, em sentido estrito, nem inconscientes, nem pré-conscientes.

Até agora, sublinhamos o fato de que o outro humano provido de inconsciente constitui, por esta razão, um pré-requisito da inteligência. Este raciocínio é incompleto se não consideramos que este outro humano também é provido de um ego. Esta questão, segundo Bleichmar (1999), é central em razão de que o ego se sustenta, como massa ligadora e defensiva interior, nos modos de ligação provenientes da mãe, quer dizer, na forma mediante a qual esta favorece a organização de circuitos de derivação de quantidades no aparelho - que, se assim não fosse, ficariam liberadas à compulsão a repetição - e abre novas vias de simbolização (associativas e de ligação). Isto se produz do seguinte modo: o outro humano exerce uma série de ações que implantam, no psiquismo do infans excitações e vias para a produção de representações e exerce essas ações para além de sua própria consciência, desconhecendo totalmente que as exerce. Esta é uma função de erogenização, de geração de sexualidade no sentido mais estrito do termo, como produção de prazer in situ. Inaugura-se, assim, uma zona erógena no lugar onde deveria haver um ponto de resolução de tensões de necessidade, abrindo-se, desta maneira, um movimento pelo qual se geram novas tensões não passíveis de solução pela via da descarga específica.
Que via de resolução tem então esta fonte inesgotável de excitações que constitui a pulsão, uma vez que se inscreveu como lugar erógenorepresentacional? Imaginemos o adulto que realiza os cuidados precoces introduzindo uma excitação pelas zonas de intercâmbio, que devém fonte de pulsão; ao mesmo tempo, deste mesmo adulto que não só dá de comer, limpa, toca pontualmente, mas também acaricia, fala, sustenta, geram-se vias de investimento frente a outras zonas, para outros pontos do corpo, vias colaterais pelas quais se produz uma circulação da quantidade e uma detenção do fluir irrefreável, abrindo-se possibilidades de derivação simbólica e de complexidade do aparelho. Estes pré-requisitos, todavia, não são suficientes, já que somente num segundo tempo, através da repressão originária e da fundação do ego sobre a base da identificação, se estabelecerá uma diferenciação tópica e um contra-investimento que fixe definitivamente no inconsciente estes modos primários de satisfação (por outra parte, o inconsciente será fundado por este movimento mesmo).

Como vemos, não é suficiente a ação excitante e de ligação do adulto; é necessário, além disso, que este narcisismo capaz de ligar, que esta visão do outro como totalidade, esteja atravessada por uma proposta de cultura na qual se impulsione o infans a aceitar certas renúncias pulsionais que abrem vias de sublimação. A repressão que a mãe exerce - repressão, neste caso, no sentido social do termo - ao impor mediante uma certa violência um corte à sua liberdade - ao propor ao infans que deixe de chupar o dedo, que deixe de fazer xixi em qualquer lugar, que deixe de tocar o ânus, tudo aquilo que diz respeito às renúncias pulsionais primárias, exercidas sob a forma de enunciados, submetidas a uma organização significante discursiva, só pode aceitar-se sobre a base de amor que circula entre ambos.

Se a sexualidade inconsciente, reprimida, do adulto, propicia a implantação da pulsão, é sua repressão, a existência de uma pauta que garanta no interior de cada cultura os limites de apropriação do corpo do outro humano, a condição da repressão originária. Desde o ponto de vista econômico, conhecemos a formulação de Freud sobre o fato de que a repressão originária é um movimento de contrainvestimento, e não a expulsão de uma representação do préconsciente. Fixação no inconsciente de algo que, uma vez recusado como modo de satisfação pulsional deixa como seqüela, do lado do ego, uma formação de caráter. É a fixação no inconsciente o que dá garantias de que essa representação não emergirá obrigando o sujeito a uma busca compulsiva da satisfação. (Bleichmar, 1999, p.124)

Vemos assim como a sexualidade parental, bem como o narcisismo e a repressão, tem correlatos com o pulsional primário e as ligações que formam o tecido básico do ego. Este bebê que a mãe sustenta, que é uma pessoa, que tem um nome, que ela cerca mediante um conjunto de representações que lhe dão uma posição no mundo, não pode ser outra ordem que a do enunciado, tem caráter discursivo: "é um menino", "como se parece com meu pai", "é muito tranqüilo", "é muito chorão", "é... é... é...”. Isto que é da ordem do enunciado parental, se plasma em ações que cumprem uma função de ligação, de derivação, que antecedem à linguagem, mas preparam o campo da sublimação, na medida em que esta só é possível sobre a base da demora da ação. 
Sabemos que o pré-consciente tem como característica a possibilidade de constituir enunciados lógicos articulados pela linguagem e que estes enunciados mostram, do lado do ego, uma profunda intolerância a tudo aquilo que ponha em risco a harmonia que o constitui - a capacidade de pensar-se a si mesmo sem contradições.

Em um segundo tempo, a repressão originária criará ao redor do ego um território fechado, no qual o sujeito poderá situar-se e serão suas próprias estruturas discursivas, operando a partir de enunciados lógicos, as que abrirão uma articulação e uma diferença entre o ego e o pré-consciente. $\mathrm{O}$ ego, enquanto resíduo libidinal destas primeiras relações tem que ver com o ligado, com o amor do outro, enquanto o pré-consciente terá que ver com formas de estruturação e contra-investimento, e com organizações de linguagem caracterizadas pela lógica formal à margem dos conteúdos.

O pré-consciente se caracteriza pela possibilidade de organizar, a partir do ponto de vista da linguagem, todas as relações lógicas, de modo tal que alguém com um quadro esquizóide grave pode ter um pré-consciente estruturado no qual o ego tenha ficado desabitado, tendo então seu discurso uma lógica impecável, porém um discurso no qual falte um sujeito que o enuncia.

Para que a lógica possa servir à organização subjetiva e a inteligência tome um caráter comunicacional, a repressão primária - que dá passo à diferença entre processos primários e secundários - não pode cair no vazio, mas sobre uma rede previamente constituída de investimentos egóicos.

Até agora, procuramos definir a inteligência na perspectiva psicanalítica, pontuando seus pré-requisitos:

1. Devem inscrever-se as representações residuais das experiências pulsionais com o outro humano;

2. Devem produzir-se ligações que regulam a passagem de investimentos entre estas experiências e que possibilitam que o psiquismo não fique liberado a um movimento meramente de auto-conservação: este é o grande paradoxo da função materna que, no momento em que satisfaz as necessidades, inclui excitações, introduz neste movimento, algo que não estava previsto no programa da natureza, produzindo uma profunda alteração nos modos automáticos de descarga e quebrando a inércia neuronal.

3. É necessário que se constituam as articulações lógicas do processo secundário abertas à significação e à relação que possibilita o conhecimento e que a repressão originária lhes dê um estatuto definitivo mediante a diferenciação entre os sistemas psíquicos.

Do lado do outro humano, a mãe coloca-se como prérequisito para que essas articulações possam instalar-se: a presença do pré-consciente no interior do qual a instância egoica dê curso a uma operatória regida pela inclusão e exclusão, pela lógica do terceiro excluído, que só pode ser concebida desde um sujeito adulto que sabe que a criança não é um apêndice de si mesmo, mas um outro diferenciado. A mãe deve possuir a categorização da realidade intersubjetiva que the permita identificar o bebê, identificar-se com ele e, ao mesmo tempo, reconhecê-lo em seu caráter de sujeito. Reconhecer o outro significa negar que o outro não é a mãe - este não ser ela afirma que o outro é. Ou vice-versa, no momento em que a mãe afirma que o bebêé, reconhece que não é ela.Vemos aqui a relação entre negação e a lógica da inclusão/exclusão.

Nesta assimetria sedutora do adulto e, ao mesmo tempo, nesta assimetria simbólica do adulto, que ama a vida da criança e ama à criança enquanto criança total - representação de um eu, existência de outro ser humano e não um punhado de pulsões, nem de corpo de gozo, mas um conjunto de representações - há um pré-requisito da inteligência que tem que ver com a capacidade de simbolizar-se como objeto desprendido do mundo, constituído como totalidade significante. (Bleichmar, 1999, pp. 308-309)

É nesta perspectiva que a autora enuncia que a repressão primária abre a possibilidade de articular enunciados lógicos e que a repressão secundária constitui os modos de inclusão e exclusão do lado do sujeito, do que pode estar no lado do préconsciente ou no ego e do que não pode estar. Esta organização da inteligência se relaciona com a abertura para as possibilidades sublimatórias e aquilo que constitui, nos termos de Freud, a pulsão epistemofílica. Freud (1905) sustentou os pré-requisitos da curiosidade intelectual em dois enigmas fundamentais que se colocam na infância: 1) de onde vêm as crianças; e, 2) por que o mundo se reparte em meninos e meninas. Ambas as perguntas estão determinadas pelo posicionamento desejante da criança em sua correlação com as figuras edípicas. São perguntas que, se em princípio têm um interesse prático, remetem não à auto-conservação, mas ao libidinal, ao desejante. Neste processamento da inteligência, a repressão originária determina, a partir da lógica da contradição, o que pode ficar no ego e o que deve ser reprimido. Bleichmar assinala que a inteligência em sentido estrito, como operatória no mundo, que toma a seu cargo as ações eficazes com a realidade, não é algo que se defina desde o inconsciente. A inteligência que possibilita uma curiosidade desperta, um interesse por aprender, não é uma questão do inconsciente, mas diz respeito ao ego.

Voltando sobre a diferença entre os sistemas, com vistas a avançar sobre a lógica operatória, observamos que a temporalidade, a negação, a lógica do terceiro excluído não estão no inconsciente, mas no pré-consciente. No inconsciente não há verdade nem mentira porque tudo é igualmente verdadeiro. A afirmação, assim como a negação, é patrimônio do pré-consciente. Quando uma criança não sabe "adiante, atrás, em cima, embaixo", não pode distinguir o "ontem do hoje" é porque não se constituiu o processo secundário, nem a posição de sujeito. A posição temporal-espacial diz respeito ao ego. Até mesmo as perguntas "quem sou eu? " ou "onde estou?", só podem ser formuladas por alguém que é, por um ego que tenta situarse. Se a repressão originária se relaciona com o fato de que há um ego fundado, não é difícil dar-se conta de por que, em geral, os mais graves transtornos da aprendizagem da primeira infância fazem evoluções psicóticas ou de déficits e não podem ser considerados como simples transtornos maturativos do desenvolvimento.

Então, se a inteligência não é uma questão do inconsciente, mas do ego e, fundamentalmente, das leis do pré-consciente, essa inteligência que permite a operatória sobre o mundo é também a que possibilita trabalhar sobre esse objeto do mundo que é o inconsciente. Desse modo, para que haja aprendizagem, tem que haver inteligência constituída, tem que haver alguém 
que possa interrogar-se sobre esta parte de si mesmo que lhe é alheia, um ego que opere com as regras do processo secundário, do pré-consciente.

\section{Conclusão}

Por mais trágico que possa ser um saber, o ser humano, inteligente, sabe de sua existência e/ou vai em busca do seu saber. Assim o fez Édipo.

Recordemos que Santo Agostinho (400/2000) disse em Confissões que os homens fazem duas perguntas: Quem sou? e Que sou?

Quem sou? respondemos a nós mesmos: "sou um homem", "sou uma mulher". Que sou? está dirigida ao Criador que deve dar conta de nossa essência. Em psicanálise, desde os primeiros tempos de vida, é a mãe quem determina quem é este outro. Ela diz: "é um ser humano" e é esta apropriação ontológica a que opera de modo constitutivo.

Os neuróticos adoecem talvez porque falhem atributos de ser; o Que sou? é a pergunta que os move. Mas em pacientes muito graves, ou em crianças que não concluíram sua constituição, o que está presente é o Quem sou? no sentido ontológico do termo, no sentido de não saber que se é um ser humano.

A inteligência deve ser pensada como adaptação, como produtora de significações e conexões, porém seu reservatório, sua fonte, não está nas conexões, mas naquilo que a agita constantemente e a obriga a ligar e organizar a tensão a que a submete o inconsciente.

Muitas vezes, sob a denominação genérica de "problemas de aprendizagem", apresentam-se situações de crianças que sequer acederam à possibilidade de aprender, que não têm a curiosidade desperta, que não possuem autoria de pensamento. Estas patologias nos remetem a revisar os movimentos que fundam o aparelho psíquico para que os transtornos graves possam encontrar vias de resolução.

Os problemas de aprendizagem podem ter múltiplas determinações, desde inadequações didáticas até aquelas dificuldades construtivas do conhecimento, determinados por fatores multicausais. Outras dificuldades de aprendizagem podem ser pensadas desde uma perspectiva psicanalítica clássica, tais como a articulação com os ideais, inibições secundárias a sintomas, mal-estares nos intercâmbios escolares, etc. Sob a denominação de dificuldades de aprendizagem podemos englobar os aspectos mais neuróticos e secundários do psiquismo e que permitem fazer intervenções, seja no plano psicanalítico, seja no plano psicopedagógico. Porém, quando falamos em transtornos da constituição do pensamento, da produção simbólica, temos de nos deter em uma visão que seja capaz de entender os processos de subjetivação e trabalhar com uma teoria adequada da simbolização e da constituição psíquica. Estamos num terreno de falhas de base para a aprendizagem, tais como a não constituição da lógica aristotélica com as categorias da classificação, da temporalidade, da negação. Estes são problemas que remetem ao não constituído do ego e tem que ser resolvido para que apareça, por um lado, a possibilidade de organização desta lógica e, por outra parte, a organização de um ser que possa perguntar-se por si mesmo e pelo universo, um lugar onde instalar-se como sujeito.

Tomando as categorias de espaço e tempo, por exemplo, podemos vê-las inibidas, mas também, podemos vê-las não constituídas. No primeiro caso, a inteligência está presente, porém, no segundo, verificamos uma impossibilidade de operar sobre o mundo, porque os processos secundários não estão constituídos, atravessados por categorias de linguagem, organizados em termos de uma lógica da contradição. Estamos falando da constituição de uma tópica que está habitada por um eu que pensa sobre si mesmo e os objetos. Se isto não se constitui, é impossível que o sujeito pense sobre o mundo, se interrogue acerca de si mesmo, construa sua permanência de ser e de seu devir.

\section{Referências}

Bleichmar, S. (1993). Nas origens do sujeito psíquico: Do mito à história (K. Ballvé Berh., Trad.). Porto Alegre: ArtMed.

Bleichmar, S. (1995). Aportes psicanalíticos para a compreensão da problemática Cognitiva. Em S. Schlemenson (Org.), Cuando el aprendizaje es un problema. Buenos Aires: Miño Y Dávila.

Bleichmar, S. (2000). Clínica psicoanalitica y neogenesis. Buenos Aires: Amorrortu.

Bleichmar, S (2001). Pensamiento-conocimiento-inteligencia: Una perspectiva psicanalítica. Em A. Castorina (Org.), Desarrollos y problemas en epistemologia genética. Buenos Aires: Eudeba.

Freud, S. (1895/1950). Projeto para uma Psicologia Científica (J. Salomão, Trad.). Em J. Salomão (Org.), Edição standart brasileira de obras completas de Sigmund Freud (Vol. I; pp. 381-533). Rio de Janeiro: Imago.

Freud, S. (1896). Carta 52 (J. Salomão, Trad.). Em J. Salomão (Org.), Edicão standart brasileira de obras completas de Sigmund Freud (Vol. I; pp. 317-324). Rio de Janeiro: Imago.

Freud, S. (1905). Três Ensaios sobre Sexualidade (J. Salomão, Trad.). Em J. Salomão (Org.), Edição standart brasileira de obras completas de Sigmund Freud (Vol. VII; pp. 123-251). Rio de Janeiro: Imago.

Freud, S. (1915). O Inconsciente (J. Salomão, Trad.). Em J. Salomão (Org.), Edição standart brasileira de obras completas de Sigmund Freud (Vol. XIX; pp. 185-239). Rio de Janeiro: Imago.

Freud, S. (1915). Repressão. (J. Salomão, Trad.). Em J. Salomão (Org.), Edição standart brasileira de obras completas de Sigmund Freud (Vol. I; pp. 339-343). Rio de Janeiro: Imago.

Laplanche, J. (1988). Teoria da sedução generalizada e outros ensaios. Porto Alegre: ArtMed. Piaget, J. (1970). A epistemologia genética. Em Os Pensadores. São Paulo, Victor Civita, 1978, caps. II e III.

Piaget, J. (1978). O nascimento da inteligência na criança ( $3^{\mathrm{a}}$ ed.). Rio de Janeiro: Zahar. Piaget, J. (1973). Biologia e conhecimento. Petrópolis, RJ: Vozes.

Piaget, J. (1982). Estudios sobre lógica y psicologia. Madrid: Ibarra.

Recebido: 02/03/2004

$1^{\text {a }}$ revisão: $13 / 04 / 2004$

Aceite final: 09/06/2004 